Research article

\title{
Seed priming with spermine ameliorates salinity stress in the germinated seedlings of two rice cultivars differing in their level of salt tolerance
}

\author{
Saikat Paul and Aryadeep Roychoudhury* \\ Post Graduate Department of Biotechnology, St. Xavier's College (Autonomous), 30, \\ Mother Teresa Sarani, Kolkata-700016, West Bengal, India \\ *Corresponding Author: aryadeep.rc@gmail.com \\ [Accepted: 02 December 2016]
}

\begin{abstract}
The present study was aimed to assess the efficacy of the tetramine, spermine (Spm) as a seed priming agent in attenuating oxidative damages and improving salt tolerance in salt-stressed seedlings of IR-64 (salt-sensitive) and Nonabokra (salt-tolerant) rice cultivars. The extent of damages was lesser in Nonabokra due to higher cysteine and ascorbic acid (AA), reducing power ability, concomitant with unaltered ascorbic acid oxidase (AAO) activity, and elevated ascorbate peroxidase (APX) and $\alpha$-amylase activity. Spm priming alleviated salt stress injury by lowering the malondialdehyde and $\mathrm{H}_{2} \mathrm{O}_{2}$ content and avoiding chlorophyll degeneration in both the cultivars, the effect being more pronounced in IR-64 in terms of $\mathrm{H}_{2} \mathrm{O}_{2}$ reduction. The intrinsic property of Spm in stress amelioration was highly evident with respect to the reduction in the levels of anthocyanin, total phenolics and cysteine, and activity of AAO and superoxide dismutase (SOD) in IR-64, whereas lowered guaiacol peroxidase (GPX), catalase (CAT) and SOD activity in Nonabokra, as compared to Spm non-primed stressed-seedlings. However, Spm priming enhanced the reducing power ability, GPX, $\alpha$-amylase and polyphenol oxidase (PPO) activities in IR-64, and anthocyanin, AA and CAT activity in Nonabokra, as means of mitigating cellular $\mathrm{NaCl}$ toxicity. A clear-cut variation in GPX, CAT, SOD and esterase isozyme profile was discernible between the two cultivars during salinity stress, with specific isoform(s) being up regulated or down regulated with Spm pre-treatment. In terms of osmolyte regulation, Spm priming appeared to be more promising in Nonabokra, because of the enhanced levels of reducing sugar, amino acids and proline. All these results indicated that seed priming with $\mathrm{Spm}$ at the pre-sowing stage can promote salinity tolerance with varying degrees in the two rice cultivars by attenuating oxidative damages, triggering the antioxidants and osmolytes, and activating the antioxidative enzymes at the protein level.
\end{abstract}

Keywords: Antioxidants - Osmolytes - Salt stress - Seed priming - Spermine.

[Cite as: Paul S \& Roychoudhury A (2016) Seed priming with spermine ameliorates salinity stress in the germinated seedlings of two rice cultivars differing in their level of salt tolerance. Tropical Plant Research 3(3): 616-633]

\section{INTRODUCTION}

Soil salinity is one of the brutal abiotic stress factors affecting crop productivity worldwide. Rice sensitivity to salt varies according to growth stage and also among the cultivars. The high yielding rice cultivars like IR-29, IR-64, IR-72, M-1-48 are salt-sensitive, whereas cultivars like Pokkali, Nonabokra, Oormundakon, etc. are low yielding, but salt-tolerant (Soda et al. 2013). Salt stress involves a combination of dehydration or osmotic stress damages due to excess accumulation of $\mathrm{Na}^{+}$ions and loss of $\mathrm{K}^{+}$ions, which adversely affects plant growth and development. Oxidative damages, invoked under salinity stress, as an early rapid response is due to the formation of reactive oxygen species (ROS), like superoxide anion $\left(\mathrm{O}_{2}{ }^{-}\right)$, singlet oxygen $\left({ }^{1} \mathrm{O}_{2}\right)$, hydroxyl radicals $\left(\mathrm{OH}^{-}\right)$and hydrogen peroxide $\left(\mathrm{H}_{2} \mathrm{O}_{2}\right)$. The ROS also trigger peroxidative reactions and cause serious damages to phospholipids, nucleic acids and proteins. To ward off such damages, plants have evolved a complex 
antioxidative system, participated by the non-enzymatic and enzymatic antioxidants (Gill \& Tuteja 2010). The enzymatic antioxidants typically include guaiacol peroxidase (GPX, EC 1.11.1.7), superoxide dismutase (SOD, EC 1.15.1.1) and catalase (CAT, EC 1.11.1.6) and enzymes belonging to the ascorbate-glutathione cycle (AsAGSH cycle) such as ascorbate peroxidase (APX, EC 1.11.1.11). In perennial rye grass (Lolium perenne L.), $\mathrm{NaCl}$ treatment enhanced the expression of SOD, CAT and peroxidase (POD) (Hu et al. 2011). Four forms of CAT isozymes, three APX isozymes and seven GPX isozymes were identified in plants under salinity stress (Lee \& An 2005). Differential changes in the level of isozyme forms might be important signals in salt stress response (Parida et al. 2004).

Under osmotic stress, the compatible solutes or osmolytes accumulate intracellularly in order to lower the osmotic potential, so as to drag more water within the cell. The common osmolytes include sucrose, proline (Pro) and glycine betaine, in addition to other molecules accumulating to high concentrations in certain species (Munns \& Tester 2008). Accumulation of Pro and mannitol has been reported under drought stress (Sickler $e t$ al. 2007). Polyamines (PAs) constitute another class of low molecular weight, nitrogeneous, aliphatic osmoprotectants. The common PAs in plants are spermidine $\left(\mathrm{Spd}^{3+}\right)$, spermine $\left(\mathrm{Spm}^{4+}\right)$ and their precursor, putrescine $\left(\mathrm{Put}^{2+}\right)$. Being polycationic in nature at physiological $\mathrm{pH}$, PAs can readily bind to the negatively charged phospholipid head group or other anionic sites on the membrane, regulating the integrity of the membrane. They also play vital role during multiple abiotic stresses including salinity, drought, low or high temperature and heavy metal toxicity (Roychoudhury et al. 2008). Being a tetramine, Spm is presumed to be a protective agent against various oxidative damages. Yamaguchi et al. (2006) found that a Spm-deficient Arabidopsis mutant exhibited hypersensitivity to $\mathrm{NaCl}$ stress. The $\mathrm{NaCl}$-hypersensitivity of the mutant could be cured by Spm but not by Put and Spd, suggesting a close link between $\mathrm{NaCl}$ hypersensitivity and Spm deficiency. Spm was found to have a protective role in detached rice leaves during water stress induced by the application of polyethylene glycol 6000 (Cheng \& Kao 2010).

Numerous attempts have been made to improve the salinity tolerance of various crops by traditional breeding program, but the progress has been quite slow with limited commercial success. Exogenous PA application increased endogenous PA levels and alleviated salt stress damages in vegetative tissues of several plants including rice. Such protective roles have been attributed to the reduction of salinity stress-induced damages (Liu et al. 2006) by inducing the activity of antioxidative enzymes and increasing the synthesis of nonenzymatic antioxidants and compatible osmolytes (Roychoudhury et al. 2011, Saleethong et al. 2011). Transgenic plants overproducing PAs, via modulating PA-metabolic pathways, rendered protection against abiotic stress conditions, while reduced in vivo PA levels resulted in decreased stress tolerance (Alet et al. 2012). Exogenously applied PAs have also been shown to effectively alleviate stress injury caused by acid rain, ozone, heavy metals, chilling and water stress (Alcázar et al. 2011). Shi et al. (2010) found that Spm pretreatment confers dehydration tolerance of Citrus plants through modulation of antioxidative potential and stomatal regulation. Since the distinct functional regulation of PAs largely depend on plant species as well varieties of the same species, deciphering the precise significance of PAs in stress response is quite complicated.

The use of some simple, cost-effective methods, such as seed priming is regarded as a pragmatic approach to overcome plant growth retardation under saline condition. Seed quality, seed germination rate and seedling vigor are altogether vital factors for sustainable crop production, particularly under adverse environmental conditions (Sun et al. 2007). Priming is a process by which seeds are exposed to restricted water availability under controlled conditions, allowing some of the pre-germination metabolic activities (physiological and chemical) to proceed, before completion of germination. This is followed by short-term storage through redrying before ultimate sowing (Farooq et al. 2010a, b). There are adequate reports showing that under diverse environmental stresses such as salinity, water deficit and extreme temperatures, osmopriming leads to cellular, subcellular and molecular changes in seeds, subsequently promoting seed vigor during germination and seedling emergence in different plant species (Beckers \& Conrath 2007). However, the efficacy of different priming agents varies under different stresses as well as in different crop species.

Although the effects of seed osmopriming with different compatible solutes and growth regulators on different plant species have been reported from time to time, little evidence exists on the effects of seed priming with Spm on germinated rice seedlings, subsequently exposed to salt stress. Using two rice cultivars with varying degrees of salt tolerance, viz., IR-64 (salt-sensitive) and Nonabokra (salt-tolerant) as experimental models, the focus of this study was to investigate if pre-soaking the seeds with Spm has the potentiality to 
ameliorate the oxidative damages in the germinated seedlings exposed to salinity stress. The efficacy of Spm as a seed priming agent in improving salt tolerance was investigated on the basis of measuring certain biochemical stress-markers (lipid peroxidation, hydrogen peroxide formation and chlorophyll degradation), analyzing the level or activity of antioxidants (non-enzymatic and enzymatic), osmolyte regulation, isozyme expression patterns and activities of the enzymes like $\alpha$-amylase and polyphenol oxidase.

\section{MATERIALS AND METHODS}

Plant materials, growth conditions and stress treatment

The seeds of Oryza sativa L. cv. IR-64 were obtained from Chinsurah Rice Research Station (Hooghly, West Bengal, India) and Nonabokra seeds from Central Soil Salinity Research Institute (Canning, West Bengal, India). The initial seed moisture content ranged between $8.5-9.5 \%$ (on a dry weight basis). The seeds were surface sterilized with $0.1 \%$ (w/v) $\mathrm{HgCl}_{2}$ for $20 \mathrm{~min}$, and washed extensively with sterile water. The seeds were pre-treated with $2.5 \mathrm{mM}$ of Spm, the concentration of Spm was chosen on the basis of earlier work by Iqbal et al. (2006). Healthy rice seeds (500 seeds for each treatment) were primed separately in $50 \mathrm{ml}$ solution of Spm or in distilled water for $8 \mathrm{~h}$ at room temperature $\left(25^{\circ} \mathrm{C}\right)$ in plastic cups. After pre-soaking, the seeds were surface dried on filter paper and allowed to dry for $12 \mathrm{~h}$ at room temperature $\left(25^{\circ} \mathrm{C}\right)$. The air-dried seeds of both the cultivars were placed on two layers of filter paper and supplemented with $75 \mathrm{mM} \mathrm{NaCl}$ for stress treatment, while distilled water was used as control (untreated). Solutions were renewed every two days. Four sets of samples were maintained:

Set 1. Water-primed seed without salt stress

Set 2. Water-primed seed with salt $(75 \mathrm{mM} \mathrm{NaCl})$ stress

Set 3. Spm-primed seed without salt stress

Set 4. Spm-primed seed with salt $(75 \mathrm{mM} \mathrm{NaCl})$ stress

The 10 day-old seedlings from each of the above sets were germinated at $32^{\circ} \mathrm{C}$, under $16 \mathrm{~h}$ light and $8 \mathrm{~h}$ dark photoperiodic cycles with $50 \%$ relative humidity and $700 \mu$ mol photons $\mathrm{m}^{-2} \mathrm{~s}^{-1}$. The seedlings were harvested, frozen in liquid nitrogen, and $0.5 \mathrm{~g}$ of each sample was used for the following estimation.

\section{Estimation of oxidative damages}

The malondialdehyde (MDA) content was estimated from $0.5 \mathrm{~g}$ of each of the samples, using MDA extinction coefficient $155 \mathrm{mM}^{-1} \mathrm{~cm}^{-1}$ (Roychoudhury et al. 2012). Hydrogen peroxide levels from $0.5 \mathrm{~g}$ of samples were determined spectrophotometrically at $390 \mathrm{~nm}$ according to Velikova et al. (2000). Total chlorophyll content from $0.5 \mathrm{~g}$ of leaf samples was estimated according to Roychoudhury et al. (2007).

Estimation of non-enzymatic antioxidant parameters [anthocyanin, cysteine (Cys), total phenolic content (TPC) ascorbic acid (AA), reducing power] and ascorbic acid oxidase (AAO, EC 1.10.3.3) activity

For anthocyanin determination, $0.5 \mathrm{~g}$ of samples was extracted with acidified $[1 \%(\mathrm{v} / \mathrm{v}) \mathrm{HCl}]$ methanol $(25$ $\mathrm{mg} \mathrm{ml}^{-1}$ ) for $24 \mathrm{~h}$ at $4^{\circ} \mathrm{C}$ with occasional shaking. The absorbance of the extract was recorded at $525 \mathrm{~nm}$ and the amount of anthocyanin was calculated using a millimolar extinction coefficient of 31.6 (Roychoudhury et al. 2007). For Cys estimation, $0.5 \mathrm{~g}$ of samples was homogenized in $5 \%(\mathrm{v} / \mathrm{v})$ chilled perchloric acid (PCA) and centrifuged at $10,000 \times \mathrm{g}$ for $10 \mathrm{~min}$ at $4^{\circ} \mathrm{C}$. The absorbance of the supernatant was measured using acidninhydrin reagent at $560 \mathrm{~nm}$ (Roychoudhury et al. 2007). The TPC in the extract was determined according to Jayaprakasha et al. (2001) with some modifications. About $0.5 \mathrm{ml}$ of the aqueous extract of each sample was mixed with $2.5 \mathrm{ml}$ of 10-fold-diluted Folin-Ciocalteu reagent and $2 \mathrm{ml}$ of $7.5 \%(\mathrm{w} / \mathrm{v})$ sodium carbonate. The mixture was allowed to stand for $30 \mathrm{~min}$ at room temperature $\left(25^{\circ} \mathrm{C}\right)$ and the absorbance was measured at 760 $\mathrm{nm}$. The final results were expressed as tannic acid equivalents. The assay of AA was performed by macerating the leaf tissues with metaphosphoric acid and titrating with $0.1 \%$ 2, 6-dichlorophenolindophenol (DCPIP) (Roychoudhury et al. 2007). The AAO activity was assayed following the method of Oberbacher \& Vines (1963). The reducing power of the rice extract was determined following Kumaran \& Karunakaran (2006), with some modifications and the absorbance was measured at $700 \mathrm{~nm}$.

Estimation of activity of antioxidant enzymes: guaiacol peroxidase (GPX, EC 1.11.1.7), ascorbate peroxidase (APX, EC 1.11.1.11), catalase (CAT, EC 1.11.1.6) and superoxide dismutase (SOD, EC 1.15.1.1)

Total protein was extracted from the samples by the method of Anderson et al. (1995). The GPX activity was determined using the method of Srinivas et al. (1999) following the formation of tetraguaiacol by 
measuring the absorbance at $470 \mathrm{~nm}$ and using an extinction coefficient $26.6 \mathrm{mM}^{-1} \mathrm{~cm}^{-1}$. The activity of APX was measured according to the method of Nakano \& Asada (1981) by estimating the rate of ascorbate oxidation (extinction coefficient $2.8 \mathrm{mM}^{-1} \mathrm{~cm}^{-1}$ ). The CAT activity was assayed by measuring the initial rate of $\mathrm{H}_{2} \mathrm{O}_{2}$ disappearance at $240 \mathrm{~nm}$ using the extinction coefficient $40 \mathrm{mM}^{-1} \mathrm{~cm}^{-1}$ for $\mathrm{H}_{2} \mathrm{O}_{2}$ (Velikova et al. 2000). The SOD activity, the basis of which is its ability to inhibit the photochemical reduction of nitroblue tetrazolium (NBT) (Beauchamp \& Fridovich 1971), was assayed following Alonso et al. (2001) with certain modifications. The unit of SOD activity was defined as that amount of enzyme which caused 50\% inhibition of the initial rate of reaction in the absence of enzyme.

In gel analysis of isozymes of GPX, CAT, SOD and esterase (EST, EC 3.1.1.43)

For in gel analysis of the isozymes of GPX, $50 \mu \mathrm{g}$ of protein was run in a non-denaturing $10 \%$ polyacrylamide gel in dark under cold condition. The specific bands were detected by submerging the gel in a staining solution containing $50 \mathrm{mM}$ potassium phosphate buffer $\mathrm{pH} 7.0,0.46 \%$ (v/v) guaiacol and $13 \mathrm{mM} \mathrm{H}_{2} \mathrm{O}_{2}$ until red bands appeared. For in gel studies of CAT, $80 \mu \mathrm{g}$ of protein was loaded in non-denaturing $10 \%$ polyacrylamide gel under cold condition. The electrophoresed samples in the gel was incubated in $0.05 \% \mathrm{H}_{2} \mathrm{O}_{2}$ (v/v) for 10 min and subsequently developed in $2 \%$ (w/v) $\mathrm{FeCl}_{3}$ and $2 \%(\mathrm{w} / \mathrm{v}) \mathrm{K}_{3} \mathrm{FeCN}_{6}$ solution for $10 \mathrm{~min}$. For in gel staining of isozymes for SOD, $80 \mu \mathrm{g}$ of protein was run through $10 \%$ native polyacrylamide gel electrophoresis in dark under cold conditions, followed by completely submerging the gel in freshly prepared staining buffer, containing $50 \mathrm{mM}$ phosphate buffer $\mathrm{pH} 7.0,0.1 \mathrm{ml}$ EDTA, $28 \mathrm{mM}$ TEMED, $0.003 \mathrm{mM}$ riboflavin and $0.25 \mathrm{mM}$ nitroblue tetrazolium for $30 \mathrm{~min}$ in dark condition. Thereafter, the gel was placed on an illuminated glass plate until the bands become visible. For detection of isozymes for EST, about $50 \mu \mathrm{g}$ of protein was run in a non-denaturing $10 \%$ polyacrylamide gel in dark under cold condition. For staining of the bands, $\alpha$-naphthyl acetate was used as a substrate and Fast Blue RR salt as a dye coupler. The staining solution consisted of $100 \mathrm{ml}$ of $0.1 \mathrm{M}$ sodium phosphate buffer $\mathrm{pH} 6.0,100 \mathrm{mg}$ Fast Blue RR salt and $0.1 \mathrm{~g}$ of $\alpha$ naphthyl acetate (acetone : water, 1: 1). The gel was incubated in the filtered solution for $30 \mathrm{~min}$ at $37^{\circ} \mathrm{C}$ in dark, and then fixed in 50\% (v/v) ethanol.

\section{Estimation of reducing sugars, total amino acids and proline}

The reducing sugar content from $0.5 \mathrm{~g}$ of samples was determined spectrophotometrically at $630 \mathrm{~nm}$ with freshly prepared anthrone reagent (Irigoyen et al. 1992). The total amino acids were quantified by the ninhydrin method according to Moore (1968). Free proline (Pro) content from the leaf samples was determined at $520 \mathrm{~nm}$ according to the procedure of Bates et al. (1973).

\section{Estimation of a-amylase (EC 3.2.1.1) and polyphenol oxidase (PPO, EC 1.14.18.1) activity}

The assay of $\alpha$-amylase activity was performed from $1 \mathrm{~g}$ of tissues (Tarrago \& Nicolas 1976) after inactivating $\beta$-amylase by heating at $70^{\circ} \mathrm{C}$ for 5 min with $9 \mathrm{mM} \mathrm{CaCl}_{2}$ and performing the assay following the standard method (Chrispeels \& Varner 1967). The PPO activity was assayed spectrophotometrically at $480 \mathrm{~nm}$ using $1 \mathrm{~g}$ of samples (Mayer \& Harel 1979).

\section{Protein estimation}

For all the enzyme assays, protein contents were estimated using bovine serum albumin (BSA) as standard (Lowry et al. 1951). Equal amount of total protein from all the test samples were used in our assay.

\section{Statistical analysis}

The experiments were carried out in a completely randomized design (CRD) with three replicates; each replication comprised an average of 50 seeds, and the results presented as means \pm standard error (SE). The data and significant differences among mean values were compared by descriptive statistics ( \pm SE) followed by Student's' $t$ '-test. The statistical significance was calculated at $P \leq 0.05$.

\section{RESULTS}

$M D A, \mathrm{H}_{2} \mathrm{O}_{2}$ and chlorophyll content

During salt stress, the MDA content increased in both the cultivars raised from water pre-treated seeds, viz., 2.2 times and 1.2 times respectively in IR-64 and Nonabokra, when compared to the control. When Spm pretreated seeds were subjected to stress imposition, the MDA content in the seedlings was reduced 1.7 folds and 1.4 folds respectively in IR-64 and Nonabokra, as compared with seedlings raised from Spm non pre-treated seeds under salinity stress conditions (Fig. 1A). Salinity stress increased $\mathrm{H}_{2} \mathrm{O}_{2}$ content 1.7 times and 1.1 times www.tropicalplantresearch.com 
respectively in IR-64 and Nonabokra seedlings germinated from water pre-treated seeds, as compared with control. The induction of $\mathrm{H}_{2} \mathrm{O}_{2}$ by salt was reduced in the seedlings raised from Spm pre-treated seeds, viz., 1.9 times and 1.2 times in IR-64 and Nonabokra respectively, as compared to the stressed seedlings without Spm pre-treatment (Fig. 1B). The chlorophyll content in salt-stressed seedlings decreased 58\% and 49\% respectively in IR-64 and Nonabokra, as compared with unstressed seedlings. However, seedlings raised from Spm pretreated seeds could overcome the salinity-induced chlorophyll loss by 32\% and 33\% respectively in IR-64 and Nonabokra, as compared to the seedlings raised from Spm non-pretreated seeds (Fig. 1C).

A

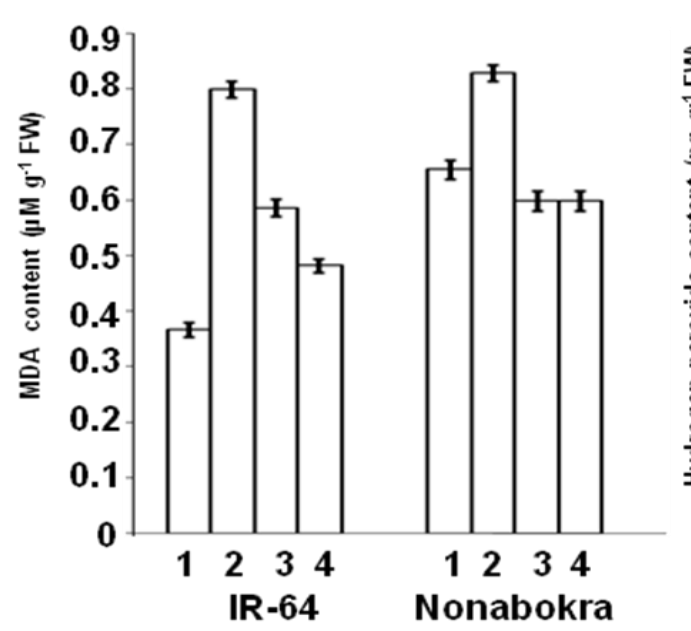

B

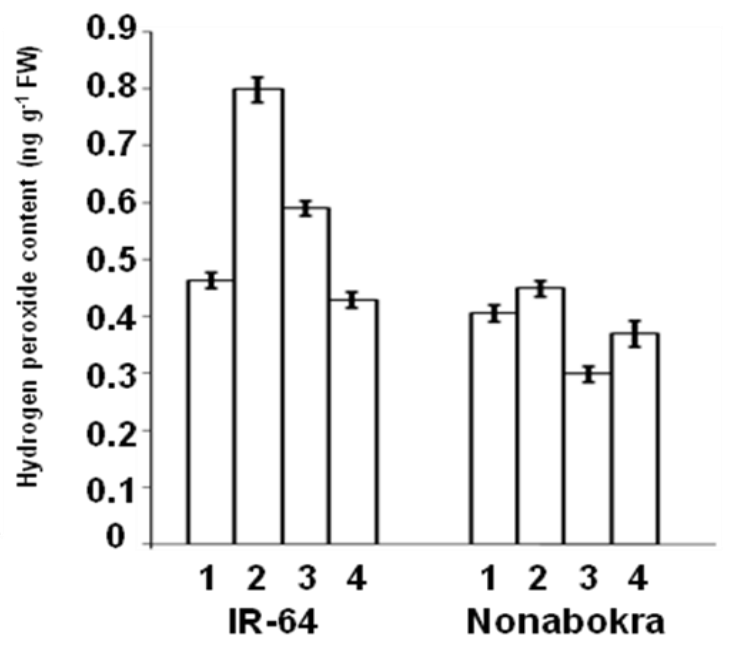

\section{C}

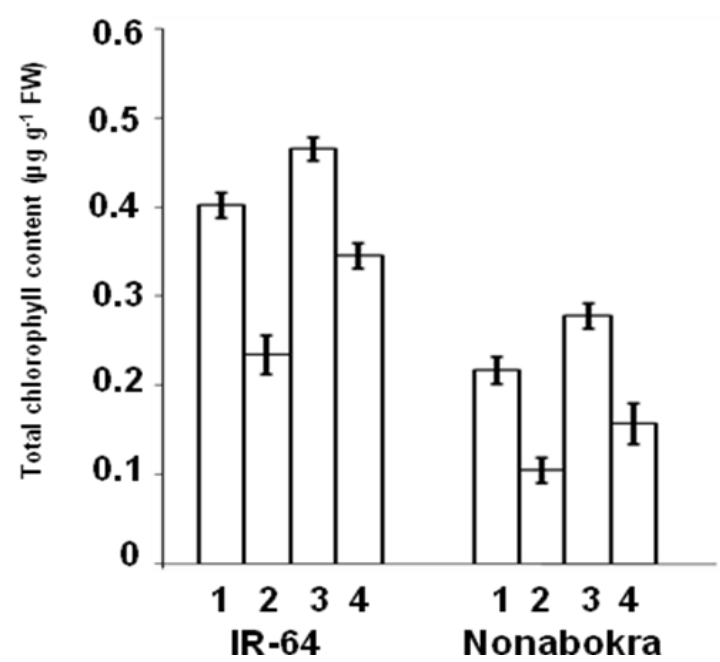

Figure 1. Effect of Spm $(2.5 \mathrm{mM})$ pre-treatment of seeds $(8 \mathrm{~h})$ on oxidative damage indices, viz., MDA content $(\mathrm{A}), \mathrm{H}_{2} \mathrm{O}_{2}$ content (B) and chlorophyll degeneration (C), in IR-64 and Nonabokra seedlings under $75 \mathrm{mM} \mathrm{NaCl}$; the stress was imposed for 10 days. The untreated seedlings (with or without Spm pre-treatment of seeds) served as experimental control. Data are the mean value $(\mathrm{n}=3) \pm \mathrm{SE}$. The SE in each case is represented by the vertical bar in each graph. Statistical differences at $P$ $\leq 0.05$ have been calculated for each t-test.

\section{Non-enzymatic antioxidant levels and AAO activity}

Salinity stress triggered the anthocyanin level almost 1.6 times in IR-64 and 1.2 times in Nonabokra, as compared with control seedlings. The stressed seedlings from Spm-treated seeds showed 2.1 times reduction in anthocyanin in IR-64, whereas 1.3 times increment in Nonabokra, relative to the Spm non-treated stressed seedlings. The anthocyanin level was considerably higher in Nonabokra (1.5 times) than IR-64 in Spm pretreated stressed seedlings (Fig. 2A). For Cys, a decrease in the level was recorded for both the cultivars during salinity stress, viz., 1.4 times and 1.1 times in IR-64 and Nonabokra respectively. Following Spm priming, the stressed seedlings showed further reduction in Cys level in both the cultivars, viz., 1.6 times and 1.8 times in IR- 
64 and Nonabokra respectively, as compared with stressed seedlings without Spm pre-treatment (Fig. 2B). Salt stress increased the AAO activity by 1.2 times in IR-64, whereas the activity remained unchanged in Nonabokra, relative to the control seedlings. Spm pre-treatment lowered the AAO activity 1.3 times in IR-64, while remaining unchanged in Nonabokra seedlings, when subjected to salt stress (Fig. 2C). The TPC in saltstressed seedlings showed 1.3 times and 1.1 times increase in IR-64 and Nonabokra respectively, as compared with control seedlings. However, exposure of seedlings from Spm pre-treated seeds to salt stress lowered the TPC, viz., 1.8 times and 1.4 times respectively, relative to the stressed seedlings in absence of Spm (Fig. 2D). With salinity stress, the AA content remained unaltered in IR-64, whereas it was induced 1.2 times in Nonabokra, as compared with non-stressed seedlings. When Spm-primed seeds were grown under salt stress, the AA content again remained almost unchanged in IR-64, whereas Nonabokra showed 1.2 times enhancement, with respect to Spm-non primed salt-treated seedlings (Fig. 2E). The reducing power in salt-stressed seedlings of IR-64 decreased drastically by 11.4 times, while 1.8 times decrease was recorded in Nonakora seedlings, with respect to the unstressed seedlings. The reducing power was enhanced particularly in IR-64 seedlings by 1.5 times, when Spm-pre-treated seeds were used, as compared with Spm non-primed samples (Fig. 2F).
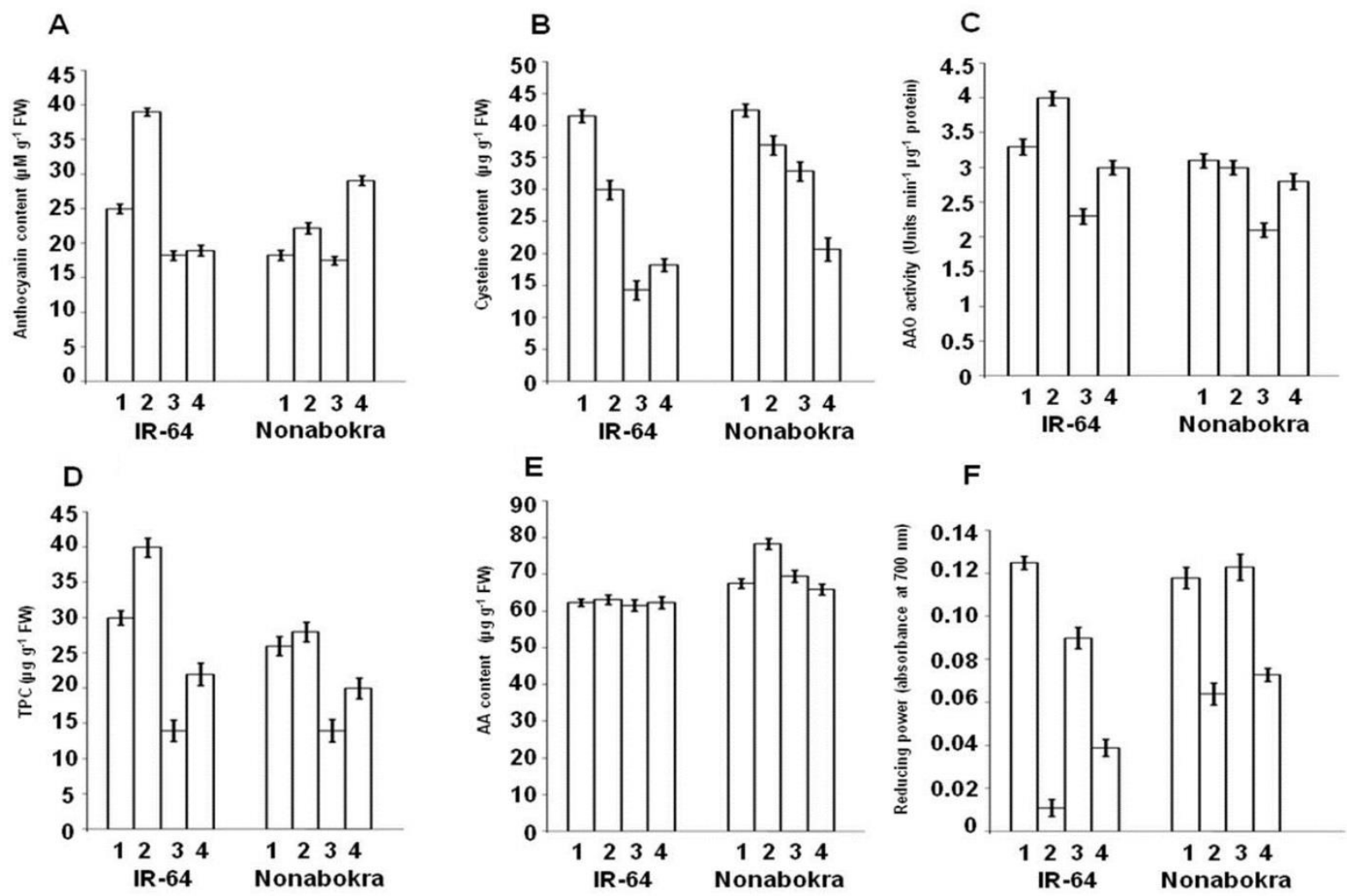

Figure 2. Effect of Spm $(2.5 \mathrm{mM})$ pre-treatment of seeds $(8 \mathrm{~h})$ on antioxidant parameters, viz., anthocyanin content (A), Cys content (B), TPC (C), AA content (D), AAO activity (E) and reducing power (F), in IR-64 and Nonabokra seedlings under $75 \mathrm{mM} \mathrm{NaCl}$; the stress was imposed for 10 days. The untreated seedlings (with or without Spm pre-treatment of seeds) served as experimental control. The data represented are means of three observations $(n=3) \pm$ SE. Statistical differences at $P \leq 0.05$ have been calculated for each t-test.

\section{Antioxidant enzyme activity}

Salinity stress increased the GPX activity 1.8 times in both IR-64 and Nonabokra, relative to the control. Spm pre-treatment drastically induced further the GPX activity, viz., 5.8 times in IR-64, while in the tolerant cultivar Nonabokra, the GPX activity was lowered 1.5 times, as compared with stressed seedlings in absence of Spm pre-treatment (Fig. 3A). The APX activity, on the contrary, showed differential response in the two cultivars. While the activity decreased 1.8 times in IR-64, it increased 1.3 times in Nonabokra after salinity stress. Seed priming with Spm induced the activity slightly in IR-64, while the activity was lowered by 1.7 times in Nonabokra during salinity stress, as compared to stressed seedlings in absence of Spm (Fig. 3B). Salinity stress increased the CAT activity 2.1 times and 1.6 times in IR-64 and Nonabokra respectively, when compared to the control. Spm pre-treatment of seeds increased the CAT activity particularly in Nonabokra (1.3 times), while in IR-64, it was almost unaltered, as compared with Spm non-treated plants under salinity stress condition www.tropicalplantresearch.com 
(Fig. 3C). Salinity stress raised the SOD activity 3.7 times in IR-64 and 4.4 times in Nonabokra seedlings relative to the control (unstressed seedlings). Spm pre-treatment of seeds, however, lowered the SOD activity in the salt-stressed seedlings of both the cultivars, viz., 3.9 times and 1.6 times respectively in IR-64 and Nonabokra, when compared to the stressed seedlings raised from Spm non-primed seeds (Fig. 3D).
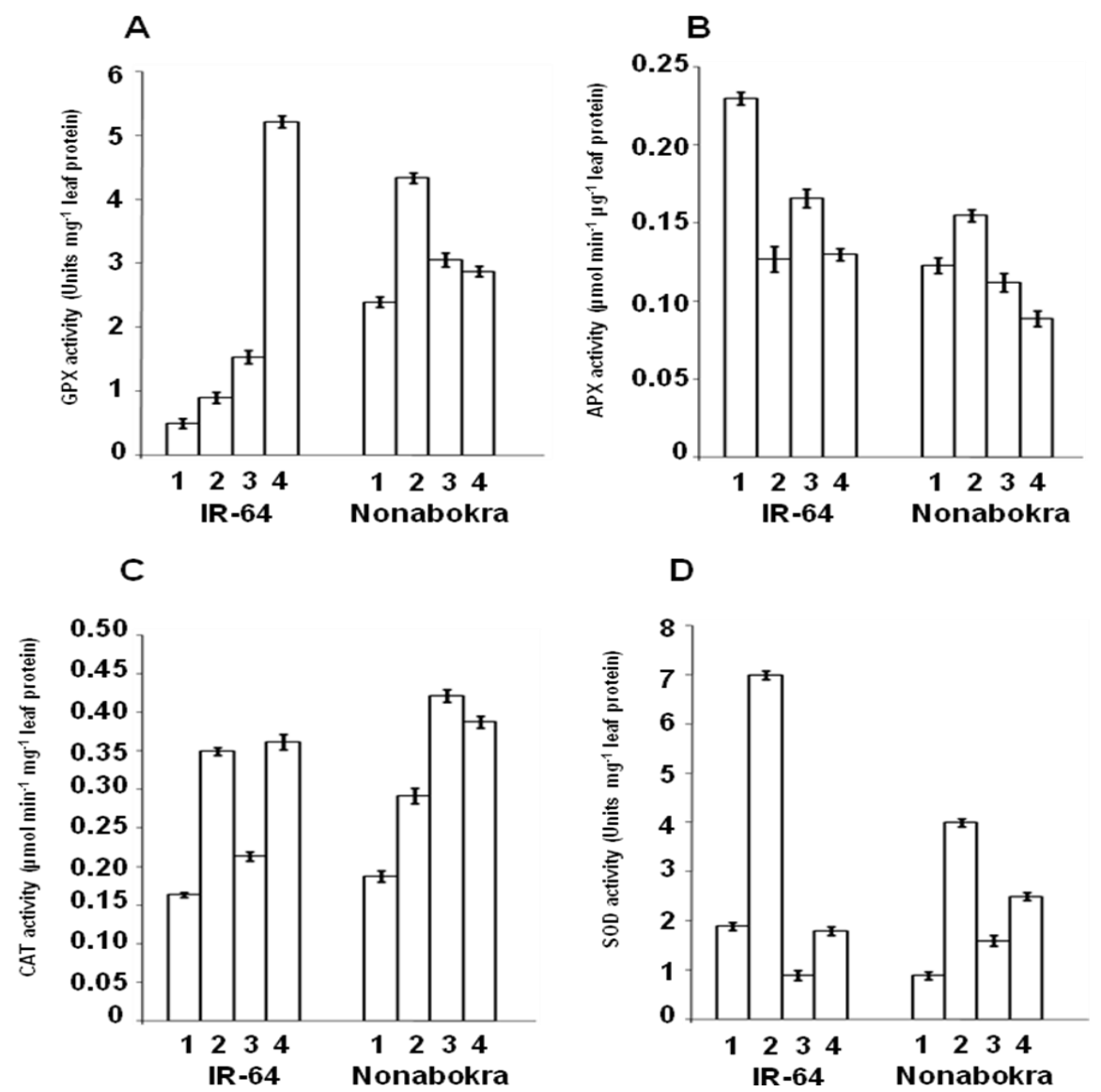

Figure 3. Effect of Spm $(2.5 \mathrm{mM})$ pre-treatment of seeds $(8 \mathrm{~h})$ on the activity of antioxidative enzymes, viz., GPX (A), APX (B), CAT (C) and SOD (D) in IR-64 and Nonabokra seedlings under $75 \mathrm{mM} \mathrm{NaCl}$; the stress was imposed for 10 days. The untreated seedlings (with or without Spm pre-treatment of seeds) served as experimental control. The data represented are means of three observations $(n=3) \pm$ SE. Statistical differences at $P \leq 0.05$ have been calculated for each t-test.

\section{Isozyme profile for the antioxidative enzymes}

While five GPX isozymes (GPX1, GPX2, GPX3, GPX4 and GPX5) were noted in IR-64, GPX5 was uninduced in Nonabokra, so that four isozymes (GPX1, GPX2, GPX3 and GPX4) were prominent. The GPX1 expression was more prominent in IR-64, while lesser induced only in the stressed seedlings of Nonabokra, whether in absence or presence of Spm pre-treatment. However, GPX2 expression was higher in Nonabokra, especially in the stressed seedlings, while weakly induced in IR-64 (Fig. 4A, 4B). Three CAT isozymes (CAT1, CAT2 and CAT3) were found in Nonabokra, while CAT3 was undetected in IR-64. The most abundant isozyme was CAT1, whose expression was almost constitutive in Nonabokra, while in IR-64, it was better induced after salinity stress and with Spm pre-treatment. Both salinity stress and Spm pre-treatment increased the intensity of CAT2 in IR-64, but undetected under control condition. The CAT2 and CAT3 inductions were higher in Nonabokra during salinity stress, while the expression was lower after Spm pre-treatment (Fig. 4C, 4D). Four SOD isozymes (SOD1, SOD2, SOD3 and SOD4) were observed in Nonabokra, of which SOD4 was undetected in IR-64. The abundance of SOD1, SOD2 and SOD3 was enhanced in IR-64 stressed seedlings raised from Spm pre-treated seeds (Fig. 4E, 4F). In case of EST, three isozymes, namely EST1, EST2 and EST3 were noted in both the cultivars. The most abundant isozyme was EST2, which was constitutively expressed in both IR-64 and Nonabokra under all the experimental conditions. The EST3 isozyme induction was considerably higher in Nonabokra than IR-64, where EST3 induction was noted upon salinity stress, with or without Spm pretreatment. Of all the isozymes, the EST1 was the most feebly induced in both the cultivars; the expression was raised after salinity stress in Nonabokra, whereas Spm pre-treatment induced the isozyme appreciably in IR-64 
(Fig. 4G, 4H).

A

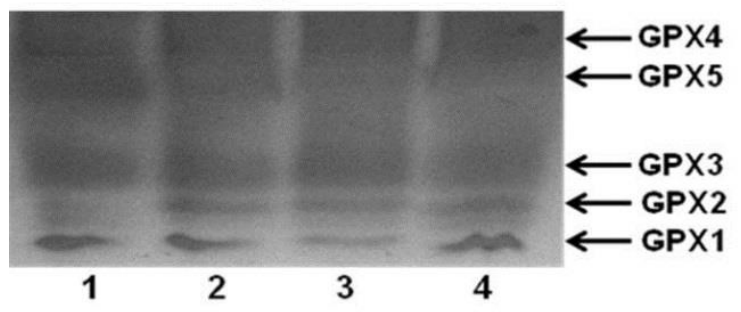

C

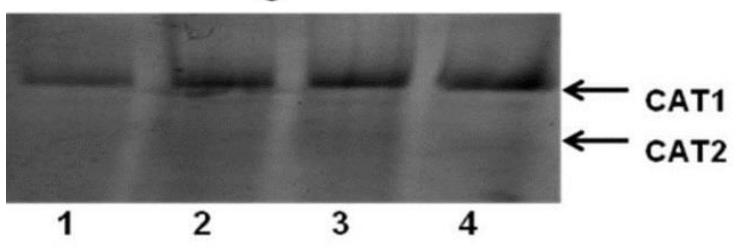

E

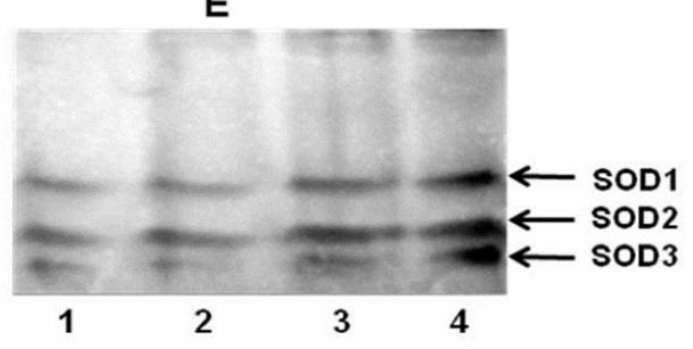

G

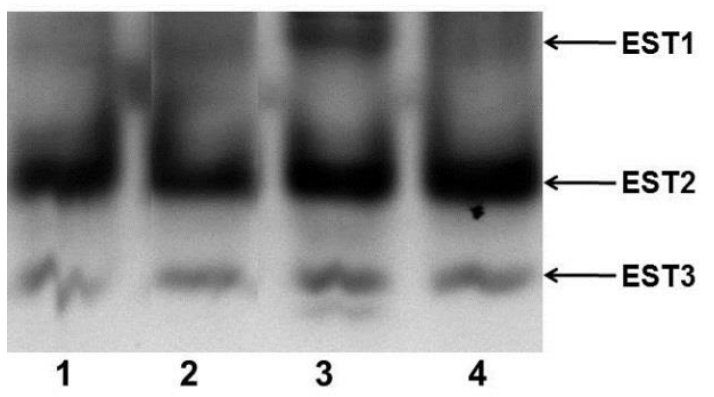

B

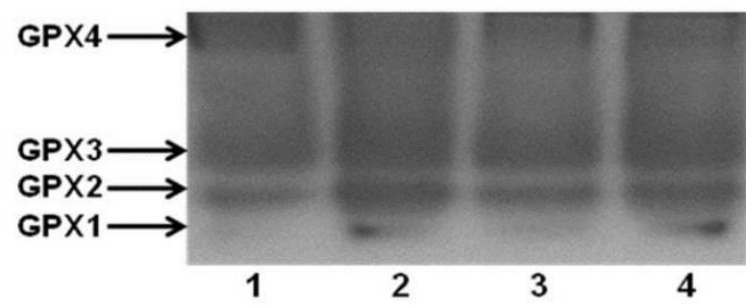

D

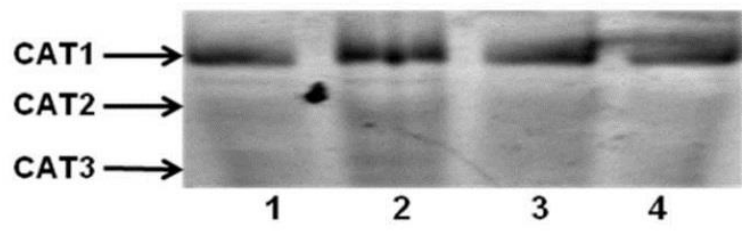

F

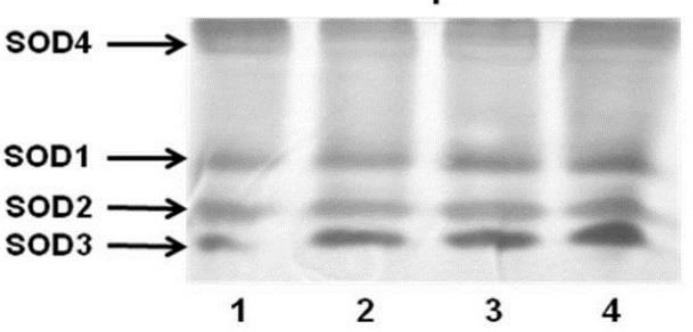

H

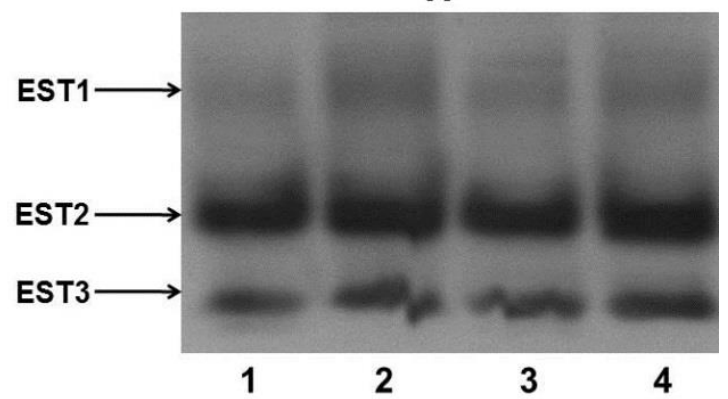

Figure 4. Effect of Spm $(2.5 \mathrm{mM})$ pre-treatment of seeds $(8 \mathrm{~h})$ on isozyme profile of GPX, CAT, SOD and EST in IR-64 (A, $\mathrm{C}, \mathrm{E}$ and $\mathrm{G}$ respectively) and Nonabokra (B, D, F and $\mathrm{H}$ respectively) seedlings under $75 \mathrm{mM} \mathrm{NaCl}$; the stress was imposed for 10 days. The untreated seedlings (with or without Spm pre-treatment of seeds) served as experimental control. The bands were resolved in non-denaturing polyacrylamide gel.

Reducing sugar, total amino acid and proline levels

Salinity stress lowered the reducing sugar content in both the cultivars, viz., 1.1 times and 1.3 times respectively in IR-64 and Nonabokra, as compared with unstressed seedlings. When Spm pre-treated seeds were germinated in presence of salt, the reducing sugar level in IR-64 seedlings remained unaffected, while that in Nonabokra seedlings increased 1.2 times, compared with the stressed seedlings without Spm pre-treatment (Fig. 5A). Upon salt stress exposure, the total amino acid level in Nonabokra decreased 1.3 times, while it remained unaltered in IR-64, with respect to the control conditions. Seedlings raised from Spm pre-treated seeds showed differential response during salinity stress. While in IR-64, the amino acid level was lowered 1.1 times, the level enhanced almost 1.8 times in Nonabokra, as compared with stressed seedlings in absence of Spm (Fig. 5B). The Pro level in both the cultivars increased with salinity stress, 1.6 times in IR-64 and 1.9 times in Nonabokra, as compared with non-stressed seedlings. Nonabokra seedlings raised from Spm primed seeds showed further enhancement in Pro level, viz., 1.2 times, while IR-64 seedlings registered 1.2 times lowered Pro level, with respect to stressed seedlings without Spm pre-treatment (Fig. 5C). 

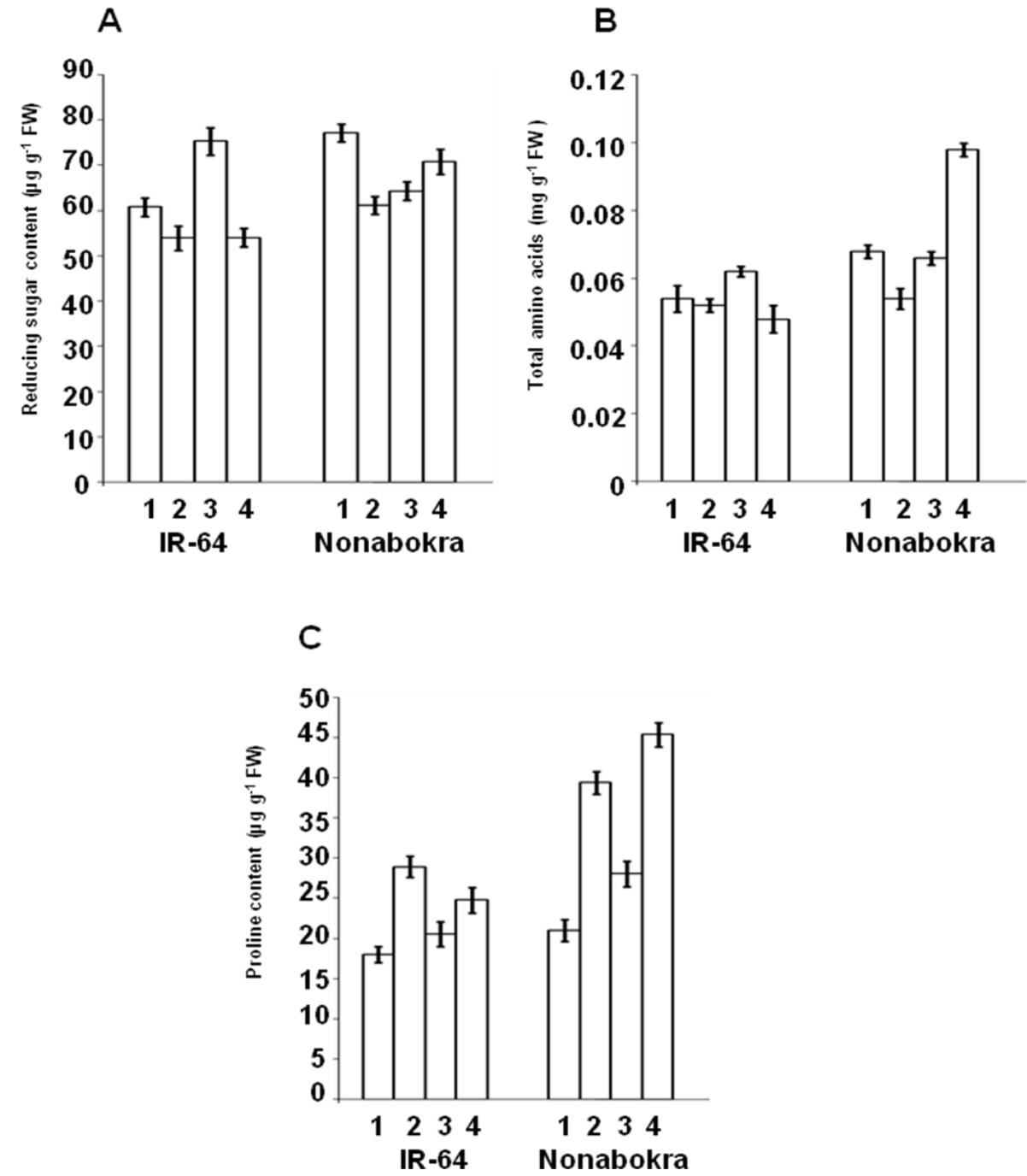

Figure 5. Effect of Spm $(2.5 \mathrm{mM})$ pre-treatment of seeds $(8 \mathrm{~h})$ on osmolyte regulation, viz., reducing sugar content (A), amino acid content (B) and Pro content (C), in IR-64 and Nonabokra seedlings under $75 \mathrm{mM} \mathrm{NaCl}$; the stress was imposed for 10 days. The untreated seedlings (with or without Spm pre-treatment of seeds) served as experimental control. The data represented are means of three observations $(\mathrm{n}=3) \pm$ SE. Statistical differences at $P \leq 0.05$ have been calculated for each $\mathrm{t}-$ test.

\section{$\alpha$-amylase and PPO activity}

The $\alpha$-amylase activity showed a differential pattern of activity in the two cultivars during salt stress. While a decreased activity was noted in IR-64, Nonabokra seedlings registered 1.4 times enhanced activity, as compared with unstressed seedlings. When Spm-primed seeds were exposed to salinity stress, the enzyme activity increased 1.1 times in IR-64, whereas it remained unaltered in Nonabokra, with respect to the salttreated seedlings without Spm pre-treatment (Fig. 6A). Salinity stress lowered the PPO activity 1.8 times in Nonabokra, while the activity was slightly triggered in IR-64, with respect to control seedlings. When Spmprimed seeds were grown under salt treatment, the PPO activity was lowered to a small extent (1.1 times) in Nonabokra, while showing a small increment (1.2 times) in IR-64, relative to the stressed seedlings without Spm application (Fig. 6B).

\section{DISCUSSION}

Priming, a prior encounter with a particular type of chemical or stress condition, is known to endow plants with greater tolerance to subsequent stress exposure of the same or different kind. Seed priming is a pre-sowing strategy that influences the seedling development at a later stage, via modulation of pre-germination metabolic activity, preceding the protrusion of the radicle (Patane et al. 2009). During priming, the seeds may be partially treated with water or various chemical solutions, so that the pre-germination metabolic activity starts, but the radicle emergence is prevented, followed by drying the seed. Improved growth and stress tolerance of the 
primed seedlings have been reported for wheat, maize, cucumber, sugarcane, lentil and capsicum (Yadav et al. 2011). Although the phenomenon is known for decades, the underlying mechanism responsible for the better performance of the primed plants under stress regimes is not well explained or understood.

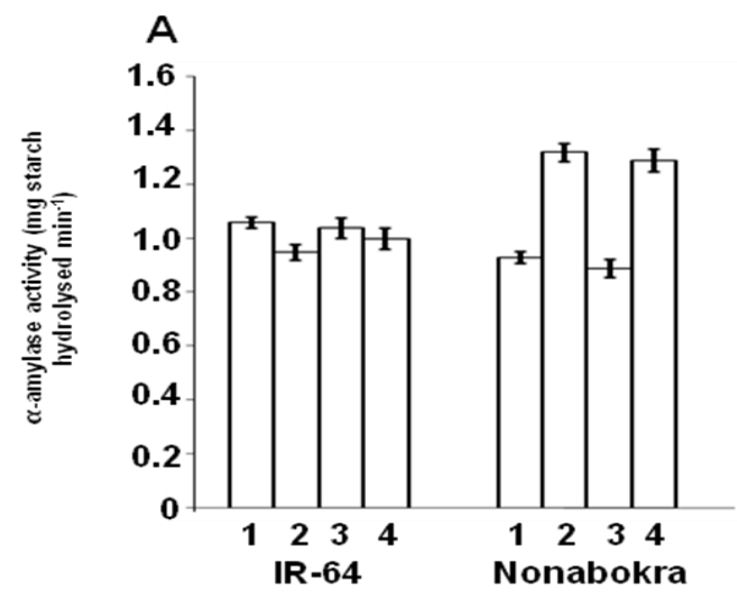

B

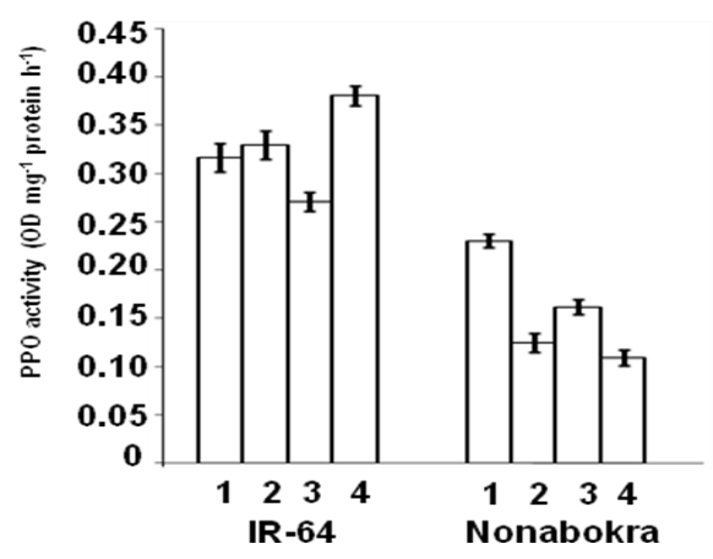

Figure 6. Effect of Spm $(2.5 \mathrm{mM})$ pre-treatment of seeds $(8 \mathrm{~h})$ on $\alpha$-amylase (A) and PPO (B) activity in IR-64 and Nonabokra seedlings under $75 \mathrm{mM} \mathrm{NaCl}$; the stress was imposed for 10 days. The untreated seedlings (with or without Spm pre-treatment of seeds) served as experimental control. The data represented are means of three observations $(n=3) \pm S E$. Statistical differences at $P \leq 0.05$ have been calculated for each t-test.

The PA accumulation in many plants is the immediate response observed in different crop species after exposure to saline conditions (Roychoudhury \& Das 2014). Most significant changes in PA levels upon salinization appear to be those of Spm, according to the data reported in rice (Maiale et al. 2004), maize (Jimenez-Bremont et al. 2007) and wheat (El-Shintinawy 2000). In most cases, Spm is more potent than Spd and considerably more efficient than Put. The more pronounced protective effect of Spm in comparison with other PAs could be accounted for by its longer chain and greater number of positive charges which allows greater neutralizing and membrane stabilizing ability. The Spm-deficient mutant Arabidopsis was found to be hypersensitive to high salt stress and this phenotype was abrogated by exogenously applied Spm (Yamaguchi et al. 2006). The ameliorative role of exogenous Spm in reproductive phase of soybean during polyethylene glycol (PEG)-induced osmotic stress has been shown, thereby improving the plant reproductive health (Radhakrishnan $\&$ Lee 2013). Since chemical priming is one of the prominent pre-germination strategies to overcome the detrimental effects associated with osmotic stresses, the effect of seed priming with Spm was assessed in the present study on the performance of seedlings of two rice cultivars, IR-64 and Nonabokra, during subsequent exposure to salinity stress.

Salinity stress led to a significant decline in the seedling quality of both the varieties by causing chlorophyll degeneration, increased MDA content and higher production of $\mathrm{H}_{2} \mathrm{O}_{2}$, though the salt-tolerant cultivar suffered lesser damages. Both chlorophyll degradation and increment of MDA content, which is a product of lipid peroxidation, are associated with the accumulation of ROS, pointing towards the damages incurred by the cell www.tropicalplantresearch.com 
membrane and chloroplast membrane in plants (Halliwell 2006). Gill \& Tuteja (2010) reported that higher accumulation of MDA declines the membrane fluidity, inactivates the receptors and degrade the membrane proteins, enzymes and ion channels. However, seed pre-treatment with Spm considerably lowered the MDA and $\mathrm{H}_{2} \mathrm{O}_{2}$ content, along with partial recovery of chlorophyll during salinity stress. The effect of Spm was more prominent in IR-64 in terms of considerable lowering of the $\mathrm{H}_{2} \mathrm{O}_{2}$ production under saline conditions. All these results are consistent with the previous studies in Arabidopsis, sunflower and soybean (Kusano et al. 2007, Radhakrishnan \& Lee 2013) where exogenous Spm could effectively overcome the deleterious effects of salinity stress.

Among the non-enzymatic antioxidants, the levels of anthocyanin and TPC showed increment with salinity stress in both the cultivars, with somewhat greater enhancement in the susceptible cultivar IR-64. Such increase is well supported by our earlier observations in rice during salinity (Roychoudhury et al. 2008) and drought (Basu et al. 2010) stress. The concerted action of low molecular weight antioxidants like anthocyanins (ChalkerScott 1999) and polyphenols (Sgherri et al. 2004) can effectively scavenge harmful radicals and stabilize the membranes against lipid oxidation under stressed conditions. Genisel et al. (2015) have reported the mitigating effect of Cys on growth inhibition in salt-stressed barley seedlings related to its own antioxidant properties. The lowered Cys content in both the cultivars, especially in IR-64, with salinity stress could be explained by the fact that more and more endogenous Cys pool is being utilized probably for the synthesis of thiol-related compounds, like glutathione or $\gamma$-glutamylcysteine-containing homologues, which maintain cellular redox homeostasis by quenching of ROS (Das \& Roychoudhury 2014). Shalata \& Neumann (2001) have shown the role of AA in increasing resistance to salt stress in tomato. Exogenous AA also increased the endogenous AA content, thereby reducing oxidative damages, with more pronounced effect in the tolerant cultivar Pokkali than in Peta, the sensitive cultivar (Wang et al. 2014). These data are in agreement with our observation where salinity stress enhanced the AA content only in the tolerant cultivar Nonabokra, concomitant with unaltered AAO activity. On the other hand, the AA content remained unaltered in IR-64, with a slightly enhanced AAO activity, signifying the better protective role of AA in Nonabokra. The suppressed expression of AAO in Nonabokra also justifies greater tolerance to salt stress than IR-64 (Yamamoto et al. 2005). The higher reducing power capability of Nonabokra during salinity stress depicts more efficient antioxidative mechanism in this cultivar in terms of free radical scavenging. The reduction in anthocyanins, TPC and Cys levels in stressed seedlings raised from Spm-primed seeds (as compared to stressed seedlings in absence of Spm) in IR-64 clearly highlights the role of Spm itself as antioxidant in mitigating oxidative stress in the salt-sensitive cultivar. However, Spm priming further elevated the anthocyanin and AA content in the stressed Nonabokra seedlings as a means to ward off the damaging symptoms. This increase is well supported by the earlier observation where Spm application induced an increment in certain antioxidants like reduced glutathione and polyphenols (Radhakrishnan \& Lee 2013). The lowered AAO activity and increased reducing power in stressed IR-64 seedlings raised from Spm-primed seeds also reflect the importance of Spm in maintaining higher AA pool with better defense mechanism in IR-64, the sensitive cultivar.

To prevent ROS from damaging various cellular components, plants have developed multiple detoxification mechanism, including the activation of various antioxidative enzymes like SOD, POD, CAT, APX and glutathione reductase. In our case, salinity stress increased the activities of GPX and CAT in both the cultivars. The elevated activities of CAT and POD were also observed in salinity-stressed cucumber (Duan et al. 2008). The activity of APX, that uses AA as the specific electron donor, increased in the salt-tolerant cultivar during stressed conditions, concomitant with the increase in AA. A similar increase in APX activity was observed in Hordeum vulgare, Plantago maritima and Brassica campestris in response to salt stress (Hernández et al. 2010). However, in our study, a decreased APX activity was recorded in the salt-sensitive cultivar IR-64. Such decrease is in accordance with earlier studies in wheat (Heidari \& Mesri 2008) and Eugenia (Acosta-Motos et al. 2015). In response to salt stress, the SOD activity increased in both IR-64 and Nonabokra seedlings, the activity being more pronounced in the sensitive cultivar. A similar increase in SOD activity was observed in salt-stressed pea, beet, maize and tomato (Azevedo-Neto et al. 2005, Koca et al. 2006). Seed priming with Spm followed by seedling exposure to salinity stress showed quite a contrasting response of all the antioxidative enzymes examined in the two cultivars. With respect to the GPX, Spm priming during salinity stress was particularly significant in the sensitive cultivar, showing a direct elevation or stimulatory effect of GPX activity, thereby rendering the tolerance mechanism in IR-64. The GPX activity, on the contrary, was down regulated by 
Spm in Nonabokra. A similar trend in Nonabokra was noteworthy with respect to APX and SOD as well, where the stressed seedlings from Spm-primed seeds showed lowered enzyme activity, compared to the stressed seedlings without Spm. This showed that Spm at the applied concentration has an intrinsic protective role during salinity stress, so that the much heightened activity of such enzymes observed during salt stress is not that prerequisite in presence of Spm. The same explanation could also hold for SOD in Spm-primed, salt-treated IR-64 seedlings, where the down regulation is strikingly noteworthy. Our observation differs from many of the earlier observations, where exogenous PA application in the form of foliar spray or hydroponic culture during salinity or drought stress, mostly increased the activity of CAT, SOD, APX and POD (Roychoudhury et al. 2011, Shi et al. 2013, Zhu et al. 2014). However, Velikova et al. (2000) showed that pre-treatment with PAs led to a reduction of POD activity in acid rain-treated bean plants. Spm priming possibly pre-disposes the seedlings to and mimics a stress-like condition and enables them for better acclimatization when they encounter the actual stress situation, so that the higher activity of the antioxidant enzymes is not obligatory even in presence of $\mathrm{NaCl}$. Yet the seedlings can manage to survive with a lowered activity of the majority of antioxidant enzymes. Thus, the anti-stress effect of PA pre-treatment during salinity stress is actually supported by the reduced defensive response rendered by the antioxidative enzymes in presence of Spm, as reported in the present work. The enhanced CAT activity with Spm in salt-treated Nonabokra is, however, in accordance with the earlier observation by Farooq et al. (2009).

Several investigations have reported varietal differences in isozyme profile with salinity stress. While four SOD activity bands were identified in the leaves of salt-tolerant Plantago maritima, only two bands were observed in salt-sensitive $P$. media. Likewise, five POD activity bands were identified in the leaves of $P$. maritima, whereas only two bands in P. media (Sekmen et al. 2007). A differential POD and SOD isozyme activities among the four potato cultivars, Agria, Kennebec (relatively salt tolerant), Diamant and Ajax (relatively salt sensitive) were noted under saline conditions (Rahnama \& Ebrahimzadeh 2006). Short-term salinity induced the expression of POD and SOD isozymes in cucumber seedlings (Du et al. 2010). In our experiment, five isozymes of GPX (GPX1-5) were noted in the sensitive cultivar, while four (GPX1-4) in the tolerant cultivar. The effect of Spm pre-treatment during salinity stress was evident from the higher induction of GPX1 in IR-64. GPX1 was however feebly induced in the stressed Nonabokra seedlings, even after Spm pretreatment. GPX5 was almost undetected in IR-64 upon Spm priming, as compared to control. Unlike IR-64, the GPX2 expression was sharper in the stressed Nonabokra seedlings, whether Spm pre-treated or not. Thus, the two varieties responded differentially with respect to GPX isozyme induction during Spm pre-treatment, with GPX1 playing more vital role in IR-64 and GPX2 in Nonabokra. In case of SOD, SOD4 was undetected in IR64, and the expression of SOD1, SOD2 and SOD3 was enhanced in the stressed seedlings of IR-64, raised from Spm pre-treated seeds. SOD3 expression was higher in Nonabokra under salinity stress. El-baky et al. (2003) observed that POD and CAT isozymes for different onion cultivars differed in number and relative concentration due to salt stress. In our study, the induction of CAT2 and CAT3 was higher in Nonabokra during salinity stress, while the expression was lower after Spm pre-treatment. The CAT1 expression in IR-64 was saltinducible and dependent on Spm treatment, whereas CAT3 expression was sharper in Nonabokra. Puyang et al. (2015) showed that pre-treatment with Spd increased the intensity of APX and CAT isozymes in both the cultivars, Kenblue and Midnight, and POD isozymes only in Kenblue cultivar of Poa pratensis. Exogenous Spd elevated the intensities of isozymes of APX, POD and SOD in alfalfa (Zhu et al. 2014). Application of exogenous Spd could also overcome oxidative damages in cucumber during salt and heat stress by causing certain changes in the zymogram expression of some antioxidant enzymes (Du et al. 2010, Tian et al. 2012). Our observation on EST showed that EST3 induction was considerably higher in Nonabokra than IR-64, where the induction was noted only after salinity stress, with or without Spm pre-treatment. EST1 was also expressed at a higher level in Nonabokra during stress, either in absence or presence of Spm. Such EST isozyme variation was reported earlier by Swapna (2002) in four rice cultivars, viz., Pokkali (moderately salt-tolerant) and M-1-48, Annapoorna and Jyothi (salt-sensitive), which indicated that this isozyme is also linked with salt tolerance. Mung bean and Sueada maritima plants, cultured under in vitro conditions, exhibited the highest EST activity between 150 and $400 \mathrm{mM} \mathrm{NaCl}$. Overall, a clear-cut variation in GPX, CAT, SOD and EST isozyme profile was discernible between the two cultivars in our work, with specific isoform(s) being up regulated or down regulated with Spm pre-treatment. 
One of the strategies to regain turgor and resume growth during ionic stresses is to accumulate osmolytes like reducing sugar, including major carbohydrates, total free amino acids and especially Pro, which synergistically reduce the osmotic potential of the cytosol to facilitate water uptake (Roychoudhury et al. 2015). Zahra et al. (2010) reported that sugar levels in rice leaves increased significantly under salt stress. However, Alamgir \& Ali (1999) observed that salinity reduced sugar content in four varieties, but increased sugar content in five other varieties. Pro and free amino acid content in the salt-stressed tissues of Pennisetum glaucum increased with increase in salt concentration as well as with duration of salt stress, thereby protecting the cellular macromolecules, maintaining the osmotic balance and also scavenging the free radicals (Sneha et al. 2013). Chutipaijit et al. (2009) reported that free Pro content of rice varieties was significantly increased with increasing salinity levels. Our observation showed a reduction in the level of reducing sugars in both the cultivars, as well as decrease in total amino acids in Nonabokra during salinity stress. Salinity stress might have led to a significant decrease in the efficiency of photosynthesis, thereby reducing the supply of soluble sugars. The soluble sugars, under such challenging situations, are probably utilized extensively for growth and maintenance of the osmotic homeostasis of cells. The reduced amino acid level could be accounted for by the fact that the amino acids are probably channelized towards the production of novel proteins during stress, rendering better tolerance in Nonabokra. Increase in free Pro level in the salt-stressed cultivars could either be due to enhanced synthesis, decreased degradation or both. The implication of Spm in increasing the level of reducing sugar in Nonabokra during salt stress is clear from our observation. Amino acids, especially Pro detoxifies plants by scavenging ROS or preventing them from damaging cellular structures (Roychoudhury et al. 2015). The constructive role of Spm priming in stress alleviation in terms of enhanced amino acid and Pro accumulation seems to be more promising in Nonabokra. The reverse trend, viz., decrease in amino acid or Pro content during salinity stress with Spm pre-treatment in IR-64 suggests an alternate mechanism by which Spm priming reduce the impact of salinity stress in the sensitive cultivar.

The influence of $\mathrm{NaCl}$ on $\alpha$-amylase activity was different in the two rice cultivars. While the activity was lowered in the sensitive cultivar, it increased to an appreciable extent in Nonabokra, signifying that sugar mobilization and hence germination was not compromised in the latter. Ashraf et al. (2002) have suggested that salt stress led to a decrease in $\alpha$-amylase activity and break down of starch into reducing and non-reducing sugars in cotton. The amylase activity decreased with increasing salinity in Phaseolus vulgaris and increased in maize. In case of rice, salt stress significantly inhibited the activity of $\alpha$-amylase during germination stage (Hualong et al. 2014), supporting our observation with IR-64. The reduction in $\alpha$-amylase activity in IR-64 could account for the reduction in concentration and translocation of free sugars into the embryo axes during germination and early growth. Exogenous Put treatment during salinity stress increased the $\alpha$-amylase activity in the growing seeds of $P$. vulgaris, thereby increasing the germination percentage of salt-stressed seeds (Zeid 2004). Tipirdamaz et al. (1995) also reported that Put, Spd and Spm significantly increased $\alpha$-amylase activity in barley seeds. Our data, showing slightly improved $\alpha$-amylase activity in stressed seedlings of IR-64 raised from Spm-primed seeds, correlates with earlier observations, indicating that adverse effect of salt stress on germination could be partially rectified in the salt-sensitive cultivar. The PPO activities were higher in bean and maize seedlings treated with $\mathrm{NaCl}$ (Tuna et al. 2013). A higher PPO activity in the leaf tissues of groundnut var. TAG-24 than in the variety TG-26 during water stress ensured better drought tolerance mechanism in the former (Shinde \& Laware 2015). Quite a contrasting result was derived in maize and Phaseolus mungo where PPO activity was decreased with increasing salinity (Dash \& Panda 2001). In our case, the PPO activity followed a different trend in the two cultivars during salinity stress, with a significant decrease in the tolerant cultivar, thereby enabling conservation of phenolics as antioxidants, while increasing to a small extent in the sensitive cultivar. Earlier reports have shown that application of Spd increased the PPO activity in the leaves of sugarbeet during salinity stress (Hajiboland \& Ebrahimi 2013). Treatment with Spd also caused PPO activation and mitigated the salinity effect in cucumber plants (Radhakrishnan \& Lee 2014). In our case, the small increment in PPO activity in salt-stressed IR-64 seedlings raised from Spm-primed seeds is in agreement with the available reports.

Although enhanced stress tolerance via exogenous PA application as foliar spray or in hydroponic culture are well documented in the available literatures, the mechanism of the protective effect of Spm pre-soaking of seeds on the performance of $\mathrm{NaCl}$-stressed, germinated seedlings is poorly studied and understood. The present communication showed that oxidative damages encountered in the two examined rice cultivars could be 
effectively attenuated with varying degrees, if the Spm pre-treated seeds are germinated and grown under salt stress. Spm itself exerts a direct antioxidative role, particularly in IR-64, thereby reducing the detrimental effect of salt stress by lowering the MDA and $\mathrm{H}_{2} \mathrm{O}_{2}$ content, and retrieving the endogenous chlorophyll content. The protective effect of Spm in Nonabokra was evidenced from the increase in osmolyte levels, rather than regulating the antioxidant machinery. Spm also effectively rendered protection against salt stress in IR-64 by enhancing the $\alpha$-amylase and PPO activity. In the nutshell, seed priming with Spm at the pre-sowing stage holds a great promise as a traditional method of agriculture in growing major staple food crop like rice under salinity regimes, so as to prevent cumulative damages and widespread crop losses.

\section{ACKNOWLEDGEMENTS}

Financial assistance from Science and Engineering Research Board (SERB), Department of Science and Technology (DST), Government of India through the research grant (SR/FT/LS-65/2010) and from Council of Scientific and Industrial Research (CSIR), Government of India, through the research grant [38(1387)/14/EMRII] to Dr. Aryadeep Roychoudhury is gratefully acknowledged.

\section{REFERENCES}

Acosta-Motos JR, Diaz-Vivancos P, Álvarez S, Fernández-García N, Sanchez-Blanco MJ \& Hernández JA (2015) Physiological and biochemical mechanisms of the ornamental Eugenia myrtifolia L. plants for coping with $\mathrm{NaCl}$ stress and recovery. Planta 242: 829-846.

Alamgir ANM \& Ali MY (1999) Effect of salinity on leaf pigments, sugar and protein concentrations and chloroplast ATPase activity of rice (Oryza sativa L.). Bangladesh Journal of Botany 28: 145-149.

Alcázar R, Marco F, Cuevas JC, Patrón M, Ferrando A, Carrasco P, Tiburcio AF \& Altabella T (2006) Involvement of polyamines in plant response to abiotic stress. Biotechnology Letters 28: 1867-1876.

Alet AI, Sánchez DH, Cuevas JC, Marina M, Carrasco P, Altabella T, Tiburcio AF \& Ruiz OA (2012) New insights into the role of spermine in Arabidopsis thaliana under long-term salt stress. Plant Science 182: 94100.

Alonso R, Elvira S, Castillo FJ \& Gimeno BS (2001) Interactive effects of ozone and drought stress on pigments and activities of antioxidative enzymes in Pinus halepensis. Plant, Cell \& Environment 24: 905-916.

Anderson MD, Prasad TK \& Stewart CR (1995) Changes in isozyme profiles of catalase, peroxidase and glutathione reductase during acclimation to chilling in mesocotyls of maize seedlings. Plant Physiology 109: 1247-1257.

Ashraf MY, Sarwar G, Ashraf M, Afaf R \& Sattar A (2002) Salinity induced changes in $\alpha$-amylase activity during germination and early cotton seedling growth. Biologia Plantarum 45: 589-591.

Azevedo-Neto AD, Prisco JT, Eneas-Filho J, de Abreu CEB \& Gomes-Filho E (2005) Effect of salt stress on antioxidative enzymes and lipid peroxidation in leaves and roots of salt tolerant and salt sensitive maize genotypes. Environmental and Experimental Botany 56: 87-94.

Basu S, Roychoudhury A, Saha PP \& Sengupta DN (2010) Differential antioxidative responses of indica rice cultivars to drought stress. Plant Growth Regulation 60: 51-59.

Bates LS, Waldren RP \& Teare ID (1973) Rapid determination of free proline for water stress studies. Plant Soil 39: 205-207.

Beauchamp C \& Fridovich I (1971) Superoxide dismutase: improved assays and an assay applicable to acrylamide gels. Analytical Biochemistry 44: 276-287.

Beckers GJM \& Conrath U (2007) Priming for stress resistance: From the lab to the field. Current Opinion in Plant Biology 10: 425-431.

Chalker-Scott L (1999) Environmental significance of anthocyanins in plant stress response. Photochemistry \& Photobiology 70: 1-9.

Cheng DG \& Kao CH (2010) Effect of exogenous spermine on polyethylene glycol-induced responses in rice leaves. Crop, Environment \& Bioinformatics 7: 233-242.

Chrispeels MJ \& Varner JE (1967) Gibberellic acid-enhanced synthesis and release of $\alpha$-amylase and ribonuclease by isolated barley aleurone layers. Plant Physiology 42: 398-406.

Chutipaijit S, Cha-Um S \& Sompornpailin K (2009) Differential accumulations of proline and flavonoids in indica rice varieties against salinity. Pakistan Journal of Botany 41: 2497-2506. 
Das K \& Roychoudhury A (2014) Reactive oxygen species (ROS) and response of antioxidants as ROSscavengers during environmental stress in plants. Frontiers in Environmental Science 2: 53.

Dash M \& Panda SK (2001) Salt stress induced changes in growth and enzyme activities in germinating Phaseolus mungo seeds. Biologia Plantarum 44: 587-589.

Du CX, Fan HF, Guo SR \& Tezuka T (2010) Applying spermidine for differential responses of antioxidant enzymes in cucumber subjected to short-term salinity. Journal of the American Society for Horticultural Science 135: 18-24.

Duan J, Li J, Guo S \& Kang Y (2008) Exogenous spermidine affects polyamine metabolism in salinity-stressed Cucumis sativus roots and enhances short-term salinity tolerance. Journal of Plant Physiology 165: 16201635.

El-baky A, Hanaa H, Amal MA \& Hussein MM (2003) Influence of salinity on lipid peroxidation, antioxidant enzymes and electrophoretic patterns of protein and isoenzymes in leaves of some onion cultivars. Asian Journal of Plant Sciences 2: 1220-1227.

El-Shintinawy F (2000) Photosynthesis in two wheat cultivars differing in salt susceptibility. Photosynthetica 38: 615-620.

Farooq M, Basra SMA, Wahid A, Khaliq A \& Kobayashi N (2010a) Rice seed invigoration: a review. In: Lichtfouse E (ed) Sustainable Agriculture Reviews, Vol. 1. Organic Farming, Pest Control and Remediation. Springer Science, pp. 137-175.

Farooq M, Wahid A \& Lee DJ (2009) Exogenously applied polyamines increase drought tolerance of rice by improving leaf water status, photosynthesis and membrane properties. Acta Physiologiae Plantarum 31: 937-945.

Farooq M, Wahid A, Lee DJ, Cheema SA \& Aziz T (2010b) Comparative time course action of the foliar applied glycinebetaine, salicylic acid, nitrous oxide, brassinosteroids and spermine in improving osmotic resistance of rice. Journal of Agronomy and Crop Science 196: 336-345.

Genisel M, Erdal S \& Kizilkaya M (2015) The mitigating effect of cysteine on growth inhibition in saltstressed barley seeds is related to its own reducing capacity rather than its effects on antioxidant system. Plant Growth Regulation 75: 187-197.

Gill SS \& Tuteja N (2010) Reactive oxygen species and antioxidant machinery in abiotic stress tolerance in crop plants. Plant Physiology and Biochemistry 48: 909-930.

Hajiboland R \& Ebrahimi N (2013) Effect of mild salinity and exogenous polyamines on growth, photosynthesis and phenolics metabolism in sugar beet plants. Iranian Journal of Biology 26: 290-300.

Halliwell B (2006) Reactive species and antioxidants. Redox biology is a fundamental theme of aerobic life. Plant Physiology 141: 312-322.

Heidari M \& Mesri F (2008) Salinity effects on compatible solutes, antioxidants enzymes and ion content in three wheat cultivars. Pakistan Journal of Biological Sciences 11: 1385-1389.

Hernández M, Fernandez-Garcia N, Diaz-Vivancos P \& Olmos E (2010) A different role for hydrogen peroxide and the antioxidative system under short and long salt stress in Brassica oleracea roots. Journal of Experimental Botany 61: 521-535.

Hu T, Li HY, Zhang XZ, Luo HJ \& Fu JM (2011) Toxic effect of $\mathrm{NaCl}$ on ion metabolism, antioxidative enzymes and gene expression of perennial rye grass. Ecotoxicology and Environmental Safety 74: 20502056.

Hua-long L, Han-jing S, Jing-guo W, Yang L, De-tang Z \& Hong-wei Z (2014) Effect of seed soaking with exogenous proline on seed germination of rice under salt stress. Journal of Northeast Agricultural University 21: $1-6$.

Iqbal M, Ashraf M, Rehman SU \& Rha ES (2006) Does polyamine seed pretreatment modulate growth and levels of some plant growth regulators in hexaploid wheat (Triticum aestivum L.) plants under salt stress? Botanical Studies 47: 239-250.

Irigoyen JJ, Emerich DW \& Sanchez-Diaz M (1992) Water stress induced changes in concentrations of proline and total soluble sugars in nodulated alfalfa (Medicago sativa) plants. Physiologia Plantarum 84: 55-60.

Jayaprakasha GK, Singh RP \& Sakariah KK (2001) Antioxidant activity of grape seed (Vitis vinifera) extracts on peroxidation models in vitro. Food Chemistry 73: 285-290.

Jimenez-Bremont JF, Ruiz OA \& Rodriguez-Kessler M (2007) Modulation of spermidine and spermine levels 
in maize seedlings subjected to long-term salt stress. Plant Physiology and Biochemistry 45: 812-821.

Koca H, Ozdemir F \& Turkan I (2006) Effect of salt stress on lipid peroxidation and superoxide dismutase and peroxidase activities of Lycopersicon esculentum and L. pennellii. Biologia Plantarum 50: 745-748.

Kumaran A \& Karunakaran RJ (2006) Antioxidant and free radical scavenging activity of an aqueous extract of Coleus aromaticus. Food Chemistry 97: 109-114.

Kusano T, Yamaguchi K, Berberich T \& Takahashi Y (2007) The polyamine spermine rescues Arabidopsis from salinity and drought stresses. Plant Signaling \& Behavior 2: 251-252.

Lee SH \& An CS (2005) Differential expression of three catalase genes in hot pepper (Capsicum annuиm L.). Molecules and Cells 20: 247-255.

Liu JH, Nada K, Honda C, Kitashiba H, Wen XP, Pang XM \& Moriguchi T (2006) Polyamine biosynthesis of apple callus under salt stress: importance of the arginine decarboxylase pathway in stress response. Journal of Experimental Botany 57: 2589-2599.

Lowry OM, Rosenbrough NJ, Farr AL \& Randall RJ (1951) Protein measurement with folin phenol reagent. Journal of Biological Chemistry 193: 265-275.

Maiale S, Sanchez DH, Guirado A, Vidal A \& Ruiz OA (2004) Spermine accumulation under salt stress. Journal of Plant Physiology 161: 35-42.

Mayer A \& Harel E (1979) Polyphenol oxidases in plants - review. Phytochemistry 18: 193-215.

Moore S (1968) Amino acid analysis: aqueous dimethyl sulfoxide as solvent for the ninhydrin reaction. Journal of Biological Chemistry 243: 6281-6283.

Munns R \& Tester M (2008) Mechanisms of salinity tolerance. Annual Review of Plant Biology 59: 651-681.

Nakano Y \& Asada K (1981) Hydrogen peroxide is scavenged by ascorbate-specific peroxidase in spinach chloroplasts. Plant and Cell Physiology 22: 867-880.

Oberbacher MF \& Vines HM (1963) Spectrophotometric assay of ascorbic acid oxidase. Nature 197: 12031204.

Parida AK, Das AB \& Mohanty P (2004) Defense potentials to $\mathrm{NaCl}$ in a mangrove, Bruguiera parviflora: differential changes of isoforms of some antioxidative enzymes. Journal of Plant Physiology 161: 531-542.

Patane C, Cavallaro V \& Cosentino SL (2009) Germination and radicle growth in unprimed and primed seeds of sweet sorghum as affected by reduced water potential in $\mathrm{NaCl}$ at different temperatures. Industrial Crops and Products 30: 1-8.

Puyang X, An M, Han L \& Zhang X (2015) Protective effect of spermidine on salt stress induced oxidative damage in two Kentucky bluegrass (Poa pratensis L.) cultivars. Ecotoxicology and Environmental Safety 117: 96-106.

Radhakrishnan R \& Lee IJ (2013) Ameliorative effects of spermine against osmotic stress through antioxidants and abscisic acid changes in soybean pods and seeds. Acta Physiologiae Plantarum 35: 263-269.

Radhakrishnan R \& Lee IJ (2014) Effect of low dose of spermidine on physiological changes in salt stressed cucumber plants. Russian Journal of Plant Physiology 61: 90-96.

Rahnama H \& Ebrahimzadeh H (2006) Antioxidant isozyme activities in potato plants (Solanum tuberosum L.) under salt stress. Journal of Sciences, Islamic Republic of Iran 17: 225-230.

Roychoudhury A, Banerjee A \& Lahiri V (2015) Metabolic and molecular-genetic regulation of proline signaling and its cross-talk with major effectors mediates abiotic stress tolerance in plants. Turkish Journal of Botany 39: 887-910.

Roychoudhury A, Basu S, Sarkar SN \& Sengupta DN (2008) Comparative physiological and molecular responses of a common aromatic indica rice cultivar to high salinity with non-aromatic indica rice cultivars. Plant Cell Reports 27: 1395-1410.

Roychoudhury A, Basu S \& Sengupta DN (2011) Amelioration of salinity stress by exogenously applied spermidine or spermine in three varieties of indica rice differing in their level of salt tolerance. Journal of Plant Physiology 168: 317-328.

Roychoudhury A, Basu S \& Sengupta DN (2012) Antioxidants and stress-related metabolites in the seedlings of two indica rice varieties exposed to cadmium chloride toxicity. Acta Physiologiae Plantarum 34: 835-847.

Roychoudhury A \& Das K (2014) Functional role of polyamines and polyamine-metabolizing enzymes during salinity, drought and cold stresses. In: Anjum NA, Gill SS \& Gill R (eds) Plant Adaptation to Environmental Change. CAB International, London, UK, pp. 141-156. 
Roychoudhury A, Roy C \& Sengupta DN (2007) Transgenic tobacco plants overexpressing the heterologous lea gene Rab16A from rice during high salt and water deficit display enhanced tolerance to salinity stress. Plant Cell Reports 26: 1839-1859.

Saleethong P, Sanitchon J, Kong-ngern K \& Theerakulpisut P (2011) Pretreatment with spermidine reverses inhibitory effects of salt stress in two rice (Oryza sativa L.) cultivars differing in salinity tolerance. Asian Journal of Plant Sciences 10: 245-254.

Sekmen AH, Türkan I \& Takio S (2007) Differential responses of antioxidative enzymes and lipid peroxidation to salt stress in salt-tolerant Plantago maritima and salt-sensitive Plantago media. Physiologia Plantarum 131: 399-411.

Sgherri C, Stevanovic B \& Navari-Izzo F (2004) Role of phenolic acid during dehydration and rehydration of Ramonda serbica. Physiologia Plantarum 122: 478-485.

Shalata A \& Neumann PM (2001) Exogenous ascorbic acid (vitamin C) increases resistance to salt stress and reduces lipid peroxidation. Journal of Experimental Botany 52: 2207-2211.

Shi HT, Ye TT \& Chan ZL (2013) Comparative proteomic and physiological analyses reveal the protective effect of exogenous polyamines in the bermudagrass. (Cynodon dactylon) response to salt and drought stresses. Journal of Proteome Research 12: 4951-4964.

Shi J, Fu XZ, Peng T, Huang XS, Fan QJ \& Liu JH (2010) Spermine pretreatment confers dehydration tolerance of citrus in vitro plants via modulation of antioxidative capacity and stomatal response. Tree Physiology 30 : 914-922.

Shinde BM \& Laware SL (2015) Investigation of water stress on antioxidant enzyme activities in groundnut varieties (Arachis hypogaea L). International Journal of Advanced Biological Research 5: 29-33.

Sickler CM, Edwards GE, Kiirats O, Gao Z \& Loescher W (2007) Response of mannitol producing Arabidopsis thaliana to abiotic stress. Functional Plant Biology 34: 382-391.

Sneha S, Rishi A, Dadhich A \& Chandra S (2013) Effect of salinity on seed germination, accumulation of proline and free amino acid in Pennisetum glaucum (L.) R. Br. Pakistan Journal of Biological Sciences 16: 877-881.

Soda N, Kushwaha HR, Soni P, Singla-Pareek SL \& Pareek A (2013) A suite of new genes defining salinity stress tolerance in seedlings of contrasting rice genotypes. Functional \& Integrative Genomics 13: 351-365.

Srinivas ND, Rashmi KR \& Raghavarao KSMS (1999) Extraction and purification of a plant peroxidase by aqueous two phase extraction coupled with gel filtration. Process Biochemistry 35: 43-48.

Sun Q, Wang JH \& Sun BQ (2007) Advances on seed vigor physiological and genetic mechanisms. Agricultural Sciences in China 6: 1060-1066.

Swapna TS (2002) Esterase as molecular marker for salt tolerance in regenerated plants of rice, Oryza sativa L. Indian Journal of Experimental Biology 40: 1056-1059.

Tarrago JF \& Nicolas G (1976) Starch degradation in the cotyledons of germinating lentils. Plant Physiology 58: 618-621.

Tian J, Wang LP, Yang YJ, Sun J \& Guo SR (2012) Exogenous spermidine alleviates the oxidative damage in cucumber seedlings subjected to high temperatures. Journal of the American Society for Horticultural Science 137: 11-19.

Tipirdamaz R, Durusoy M \& Bozcuk S (1995) Effect of exogenous polyamines on alpha-amylase activity during seed germination under salt stress. Turkish Journal of Botany 19: 411-416.

Tuna AL, Kaya C, Altunlu H \& Ashraf M (2013) Mitigation effects of non-enzymatic antioxidants in maize (Zea mays L.) plants under salinity stress. Australian Journal of Crop Science 7: 1181-1188.

Velikova V, Yordanov I \& Edreva A (2000) Oxidative stress and some antioxidant systems in acid rain-treated bean plants: protective role of exogenous polyamines. Plant Science 151: 59-66.

Wang R, Liu S, Zhou F, Ding C \& Hua C (2014) Exogenous ascorbic acid and glutathione alleviate oxidative stress induced by salt stress in the chloroplasts of Oryza sativa L. Zeitschrift fur Naturforschung C 69: 226236.

Yadav PV, Kumari M \& Ahmed Z (2011) Seed priming mediated germination improvement and tolerance to subsequent exposure to cold and salt stress in capsicum. Research Journal of Seed Science 4: 125-136.

Yamaguchi K, Takahashi Y, Berberich T, Imai A, Miyazaki A, Takahashi T, Michael A \& Kusano T (2006) The polyamine spermine protects against high salt stress in Arabidopsis thaliana. FEBS Letters 580: 6783- 
6788.

Yamamoto A, Bhuiyan MNH, Waditee R, Tanaka Y, Esaka M, Oba K, Jagendorf AT \&Takabe T (2005) Suppressed expression of the apoplastic ascorbate oxidase gene increases salt tolerance in tobacco and Arabidopsis plants. Journal of Experimental Botany 56: 1785-1796.

Zahra S, Amin B, Ali VSM, Ali Y \& Mehdi Y (2010) The salicylic acid effect on the tomato (Lycopersicum esculentum Mill.) sugar, protein and proline contents under salinity stress $(\mathrm{NaCl})$. Journal of Biophysics and Structural Biology 2: 35-41.

Zeid IM (2004) Response of bean (Phaseolus vulgaris) to exogenous putrescine treatment under salinity stress. Pakistan Journal of Biological Sciences 7: 219-225.

Zhu KK, Zhang J, Cui WT, Jin QJ, Samma MK \& Shen WB (2014) Role of heme oxygenase-1 in spermidineinduced alleviation of salt toxicity during alfalfa seed germination. Plant Soil 375: 275-287. 